\title{
México en la política exterior de Polonia desde el 2004
}

\author{
Mexico in Poland's foreign policy since 2004
}

Bartłomiej Znojek ${ }^{2}$

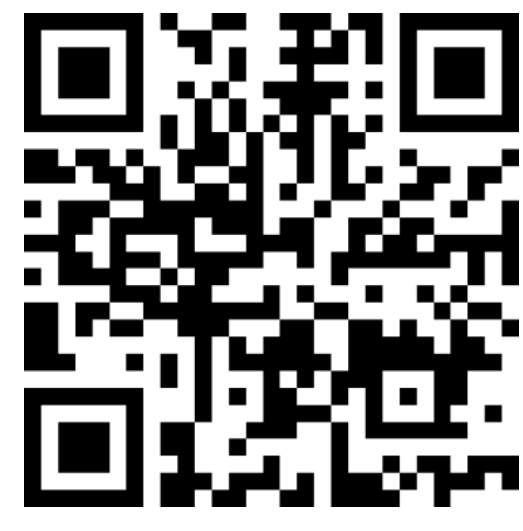

Fecha de recibido: $19-03-2021$

Fecha de aceptado: 14-05-2021

\section{(c) BY-NC-ND}

Esta obra está bajo una licencia de Creative Commons Reconocimiento-NoComercialSinObraDerivada 4.0 Internacional

\section{RESUMEN}

El objetivo de este artículo es caracterizar la política exterior de Polonia hacia México desde 2004 - el año de la adhesión de Polonia a la Unión Europea (UE). Para este fin se analizó el discurso oficial y documentos de los sucesivos gobiernos de Polonia y se presentó el desarrollo las relaciones polaco-mexicanas en tres ámbitos: político, económico y sociocultural. América Latina no pertenece a las principales áreas de interés internacional de Polonia y los gobiernos polacos se concentraban más bien en las economías más grandes de la región. El análisis en este texto muestra, que durante el período en cuestión México se convirtió en un socio latinoamericano clave para Polonia. Este resultado fue favorecido por un marco sólido y avanzado de las relaciones UEMéxico, así como por un creciente interés de Polonia en los mercados menos explorados, pero prometedores, como el mexicano y de la Alianza del Pacífico en sentido más amplio. El desafío para las relaciones polaco-mexicanas consiste en fomentar más interés mutuo y asegurar la continuidad de varios compromisos bilaterales acordados en los últimos años.

Palabras claves: México, política exterior, Polonia, relaciones bilaterales, Unión Europea.

\begin{abstract}
The aim of the article was to characterize the Polish foreign policy towards Mexico since 2004 - the year of Poland's accession to the European Union (EU). For that end the official discourse and documents of successive Polish governments on their foreign policy were analyzed and the development of the Polish-Mexican relations in three areas: political, economic and sociocultural was presented. Latin America has not been among the main areas of international interest for Poland, and the Polish governments rather concentrated on the largest region's economies. The analysis in this text shows that in the concerned period Mexico has become a key Latin American partner for Poland. That was favored by a robust and an advancing framework for EU-Mexican relations, as well as an increasing interest of Poland in the less explored, but promising markets such as Mexico and the Pacific Alliance more broadly. The challenge for Polish-Mexican relations is to foster mutual interest and ensure the continuity of the various bilateral commitments agreed in recent years.
\end{abstract}

Keywords: Bilateral relations, European Union, foreign policy, Mexico, Poland.

Cómo referenciar este artículo:

Znojek., B. (2022). México en la política exterior de Polonia desde el 2004. Revista Política, Globalidad y Ciudadanía, 8(15), 68-91. https://doi.org/10.29105/pgc8.15-4

\footnotetext{
${ }^{1}$ Este artículo se preparó en respuesta a la convocatoria anunciada por la Embajada de México en Polonia en cooperación con esa Revista. Iniciado en septiembre 2020 y finalizado en octubre 2020.

${ }_{2}^{2}$ Instituto Polaco de Asuntos Internacionales (PISM), Polonia. Licenciado en Relaciones Internacionales y en Estudios Latinoamericanos por la Universidad Jaguelónica, investigador de América Latina, Instituto Polaco de Asuntos Internacionales (PISM). Email: znojek@ pism.pl ORCID: 0000-00027242-0069.
}

68 Revista Política, Globalidad y Ciudadanía | Vol. 8, Núm. 15, enero - junio 2022 | ISSN 2395-8448 | http://revpoliticas.uanl.mx/ 


\section{1. - INTRODUCCIÓN}

La entrada de Polonia en la Unión Europea en 2004 junto al acceso a la OTAN en 1999 eran culminación del objetivo supremo de la reintegración con Europa definido en el proceso de la transición democrática iniciado en el umbral de las décadas 1980 y 1990. La membresía en la UE cambiaba la perspectiva de como conceptualizar la política exterior polaca y requería pensar más en las relaciones con socios más distantes, pero importantes para la Unión.

México es particularmente interesante por el grado más avanzado de las relaciones con el bloque comparando con otros países de América Latina. Fue el primer país de la región en firmar acuerdo de asociación con la UE y recientemente de un pacto modernizado, así como también es uno de los socios estratégicos de la Unión.

La mejora de la posición de Polonia en la UE depende de la capacidad de gobiernos polacos de expandir relaciones con socios extrarregionales más distantes, pero importantes para la Unión, como México. Por eso es oportuno estudiar cómo los gobiernos polacos definían y realizaban su política hacia este país.

Una importante motivación de la selección del tema para este estudio, es también que, el problema de la política de Polonia hacia México a partir del 2004 cuenta con interés analítico y académico muy escasos. Hallan se principalmente en unos análisis dedicados a la política polaca hacia América Latina en general - aquí destacan trabajos de Wojna (2006), Znojek (2018) y recientemente de Łapaj-Kucharska (2020). En caso de las relaciones polaco-mexicanas después de la entrada de Polonia en la UE como tema separado apenas se puede mencionar un estudio de Brudzińska (2013).

Como Polonia es una democracia parlamentar - el presidente del país es su máximo representante - el primer ministro es jefe del gobierno. El consejo de ministros es responsable por la conducción de la política del país. Este artículo se basa en las declaraciones y documentos de cuatro sucesivos gobiernos del período analizado. Se analizó sobre todo declaraciones anuales del programa de la política exterior habitualmente presentados por los ministros de asuntos exteriores en Sejm - cámara baja del parlamento polaco - y documentos estratégicos públicos del gobierno sobre las relaciones internacionales de Polonia. Después se revisó el desarrollo de las relaciones polaco-mexicanas en tres ámbitos: dialogo político, cooperación económica y relaciones socioculturales, incluidas la educación, ciencia y turismo. 
Znojek., B.

\section{2.- FUNDAMENTO TEÓRICO}

\section{Condiciones}

América Latina no pertenece a las principales áreas de la política exterior de Polonia (Sejm RP, 2004a; Znojek, 2018) y los gobiernos polacos tradicionalmente centraron su interés en las economías más grandes de la región. Por lo tanto, México era siempre incluido entre los principales socios latinoamericanos de Polonia. La adhesión polaca a la Unión Europea (UE) el 1 de mayo de 2004 ha creado nuevas condiciones para el desarrollo de contactos polaco-mexicanos.

Como miembro de la UE Polonia se convirtió estado parte y el beneficiario de los acuerdos comerciales negociados por la Unión, como él suscrito con México en el 1997 cuyas preferencias estaban entrando en vigor a partir del 2000 (Oberda-Monkiewicz, 2017). Además, las autoridades polacas podían

participar en el proceso de la formación de la política latinoamericana de la UE, por ejemplo, en el establecimiento de la asociación estratégica entre la Unión y México en 2009. De todos modos, fue la crisis financiera mundial de 2008, un impulso significante para un mayor interés de los gobiernos polacos en avanzar la internacionalización de empresas especialmente en los mercados menos explorados.

La fundación de la Alianza del Pacífico en 2012 por México, Chile, Colombia y Perú, y luego el progreso relativamente rápido de la iniciativa, fueron factores que llamaron la atención de las autoridades polacas. El interés de Polonia en México se vio fomentado aún más por las negociaciones sobre la modernización del acuerdo de la UE con México, que comenzaron en 2016 y concluyeron en 2018. Finalmente, un momento particular de la intensificación de las relaciones polaco-mexicanas se produjo con la histórica visita del presidente polaco Andrzej Duda a México en abril de 2017 y la suscrición de una declaración sobre la voluntad y el interés de construir una relación estratégica entre ambas naciones. La intensificación de los contactos políticos fue acompañada por un notable fortalecimiento de la cooperación científica y académica, pero también por un creciente interés por México en Polonia derivado de un bastante buen reconocimiento en la sociedad polaca de la cultura y atractividad turística mexicanas.

En caso de la representación oficial de Polonia en México, es importante subrayar que, la embajada polaca en algunos períodos tenía una responsabilidad territorial bastante amplia. El embajador polaco fue acreditado también en Antigua y Barbuda (los años 2005-2007), República Dominicana 
(2003-2007) y Haití (2001-2007). Con el cierre de la embajada polaca en Costa Rica en 2008 - justificado por el gobierno polaco con el motivo de la austeridad - la acreditación se extendió a seis países centroamericanos - aparte de Costa Rica, también Belice, Guatemala, Honduras, Nicaragua y El Salvador. Las autoridades insistieron entonces en el desarrollo de la red de consulados honorarios. En México había siete representaciones de este tipo en 2008 - últimamente una menos. La situación ha cambiado con el restablecimiento de la Embajada de Polonia en Panamá en 2019 - la representación asumió parte de la responsabilidad territorial mantenida por la embajada en México. En 2018, se inauguró la oficina de agregado de defensa polaco en la Ciudad de México (Sejm RP, 2008, 2018; Smolana, 2018).

\section{Principios y objetivos}

El contenido de la política de Polonia hacia México formulada desde el 2004 era función de un concepto más amplio sobre América Latina y del contexto asociado con la membresía polaca en la UE. Sin embargo, se mantuvo cierta continuidad independientemente de los cambios de las fuerzas políticas en el poder. En vísperas de la adhesión de Polonia a la UE, el entonces ministro de asuntos exteriores Włodzimierz Cimoszewicz en gobierno de izquierda del primer ministro Leszek Miller, sostuvo que la entrada en la UE, iría a influir la posición del país en el mundo y el rumbo del desarrollo de sus relaciones bilaterales con países no europeos, incluidos los latinoamericanos. Indicó que Polonia iría a participar en varias plataformas del dialogo internacional de la Unión como las cumbres interregionales UE-América Latina y el Caribe, e iría a participar en el proceso de desarrollo de contactos políticos con la región. Cimoszewicz definió México, junto a Argentina, Brasil y Chile como socios latinoamericanos prioritarios para Polonia (Sejm RP, 2004b).

La exposición del ministro fue elaborada en La Estrategia de la República de Polonia hacia los países en desarrollo no europeos publicada por la cancillería polaca en noviembre de 2004 (Ministerio de Asuntos Exteriores de Polonia, 2004). Según el documento el atractivo de América Latina, esto se debía principalmente a las posibilidades de cooperación económica relacionada a la abundancia de materias primas y desarrollo industrial de la región. La selección de Argentina, Brasil, Chile y México como socios prioritarios fue explicada por la creciente presencia de estos países en los mecanismos multilaterales de cooperación (el documento mencionaba también Colombia y Venezuela como "socios importantes" de Polonia).

La distinción de México en el documento se debía, por ejemplo, a su pertenencia a OCDE (desde 1994), a APEC, a TLCAN y a su condición de observador en las cumbres del G8. Entre factores 
Znojek., B.

favorables para el fomento de las relaciones con México La Estrategia mencionaba los buenos pronósticos económicos, el potencial de sus recursos de petróleo y gas, un sistema político y una economía relativamente estables, y una estrecha cooperación con la UE. En el marco bilateral ayudaba un diálogo y la cooperación regulares en los ámbitos científico y cultural. Entre las dificultades se hablaba de la elevada deuda de México, la agravación de la seguridad pública y las cuestiones contenciosas relativas a los procedimientos veterinarios (por ejemplo, unos controles largos y costosos de leche en polvo).

En una década, desde la publicación de La Estrategia del 2004, las presentaciones oficiales de programas de la política exterior en principio no salían más allá de las declaraciones generales de interés en la cooperación con América Latina. Por ejemplo, la región fue apenas mencionada en las presentaciones anuales de Radosław Sikorski, canciller polaco de 2007 a 2014 durante los dos mandatos del gobierno centroderechista del primer ministro Donald Tusk. La excepción fue un discurso en 2013, en el que Sikorski mencionó la creciente presencia de empresas polacas en mercados no europeos menos explorados (Sejm RP, 2012).

Las palabras del canciller mencionado se produjeron un año después de la adopción de las Prioridades de la política exterior polaca 2012-2016 por el Consejo de Ministros. En el texto se argumentaba a favor de la necesidad de aumentar la presencia de Polonia fuera de las destinaciones tradicionales y, con respecto a América Latina, el énfasis en las políticas climática y energética como áreas importantes de cooperación (Brudzińska, 2013; Consejo de Ministros del Gobierno de Polonia, 2012).

El sucesor de Sikorski - Grzegorz Schetyna (el canciller de agosto de 2014 a noviembre de 2015) argumentaba por una mayor presencia de Polonia en América Latina. Insistía en trabajar con la Alianza del Pacífico - vista como un bloque prometedor de integración económica. Sin embargo, entre distintos países latinoamericanos destacó Brasil como "un socio estratégico importante de Polonia” (Sejm RP, 2015).

En mayo de 2015, la cancillería polaca publicó el documento Desafíos en La Política Exterior de la República de Polonia hacia América Latina y el Caribe 2015-2020 y después de 2020. El texto no tenía carácter de una posición oficial del Ministerio, pero de hecho consistió el intento más significativo 
desde 2004 de la presentación de propuestas para la política latinoamericana de Polonia. Se definieron México y Brasil como socios claves de Polonia en la región.

En caso de las relaciones polaco-mexicanas, se proponía en los Desafíos el enfoque principal en la cooperación económica (por ejemplo, aprovechando las oportunidades derivadas de las reformas estructurales en México) y política, por ejemplo, dentro de la ONU. En una sección separada la publicación describía el potencial de la Alianza del Pacífico llamándola una iniciativa de integración regional destacada por las redes de acuerdos comerciales de sus miembros y un proceso ágil de la liberalización de comercio dentro del bloque. Según la publicación, la Alianza se debía convertir en uno de los principales rumbos de expansión económica polaca y desarrollo del diálogo político en América Latina. Para lograr estos objetivos se recomendaba conseguir para Polonia el estatus de observador en la organización (Hinz, 2015).

La toma del poder en Polonia por el gobierno conservador del partido Ley y Justicia en noviembre 2015 abrió un proceso de mayor interés en América Latina. En la presentación de los objetivos de política exterior en enero de 2016 del gobierno de Beata Szydło, el canciller Witold Waszczykowski anunciaba planes del fortalecimiento de cooperación económica con los socios de la región y el restablecimiento de las embajadas polacas en Panamá y Ecuador (Sejm RP, 2016). Un año más tarde, enfatizaba un prometedor carácter de las relaciones con la Alianza del Pacífico y la intención de dar a las relaciones con México un carácter estratégico con motivo de la planeada visita del presidente Andrzej Duda en aquel país (Sejm RP, 2017b). En aquel momento México fue un interlocutor importante en los esfuerzos de las autoridades polacas para conseguir apoyo a la candidatura de Polonia para ser miembro nopermanente del Consejo de Seguridad de la ONU en el período 2018-2019.

En noviembre de 2016, se publicó el documento Recomendaciones para el fortalecimiento de las relaciones entre Polonia y México preparado por las cancillerías de ambos países. La iniciativa tenía sus comienzos en 2015 durante las reuniones bilaterales de representantes de gobiernos. El texto fue preparado a base de consultas en las administraciones estatales, pero también instituciones académicas y de análisis internacional en Polonia y México. Según las Recomendaciones, la cooperación económica iba a ser la más importante en las relaciones bilaterales y debía fortalecerse en el futuro gracias a la implementación del acuerdo modernizado UE-México. Entre factores favorables para una cooperación más estrecha se mencionaba la pertenencia de Polonia y México a la OCDE y sus experiencias como participantes de las misiones de paz (Secretaría de Relaciones Exteriores de México, 2016) 
En julio de 2017 el gobierno publicó la Estrategia Polaca de Política Exterior 2017-2021, en la que señaló América Latina como un área para una mayor diversificación geográfica de la actividad económica polaca en el mundo. El texto no enumeraba socios individuales, pero entre los objetivos hacia países no europeos mencionaba esfuerzos de Polonia para reducir obstáculos en área de comercio, incluido el apoyo para contenido favorable en los acuerdos negociados por la UE. Además, destacó su voluntad de cooperar con países latinoamericanos en el campo de la investigación y la innovación, y de promover el turismo a Polonia (Ministerio de Asuntos Exteriores de Polonia, 2017).

Las líneas de la política hacia América Latina ocuparon una considerable parte de la información del gobierno sobre el programa de política exterior polaca en 2019 presentada por el canciller Jacek Czaputowicz. Con respecto a México el ministro subrayaba los empeños para fomentar relaciones bilaterales conforme con las declaraciones y los compromisos de la visita del presidente Duda en México en abril 2017. Acentuaba también la importancia del estatus de observador en la Alianza del Pacífico concedido a Polonia en julio 2015. Denominó la Alianza como “el bloque con el desarrollo más dinámico" de América Latina (Sejm RP, 2019b).

\section{Cooperación política}

El diálogo polaco-mexicano desde el 2004 se caracterizaba por una intensidad bastante baja de contactos en el nivel más alto (situación semejante a las relaciones con otros mayores socios latinoamericanos de Polonia, como Brasil). La oportunidad para reunirse entre líderes le daban cumbres de la UE con los socios latinoamericanos o las reuniones en diversos foros internacionales, especialmente la Asamblea General de las Naciones Unidas.

Desde la entrada de Polonia en la UE, hubo dos visitas oficiales de los representantes más altos. En mayo de 2004, el presidente mexicano Vicente Fox Quesada viajó a Polonia, donde fue recibido por el presidente Aleksander Kwaśniewski (Sejm RP, 2004a; Oficina de Presidente de Polonia, 2004). Fue la primera visita del máximo representante de México en Polonia desde el 1963. Durante la visita las dos partes firmaron un acuerdo de cooperación en el ámbito del turismo (un acuerdo bilateral sobre la exención de visados estaba en vigor desde 1999). Además, se creó un grupo bilateral de expertos denominado "think tank" y encargado de análisis y elaboración de recomendaciones sobre el desarrollo de la cooperación en el ámbito económico (Sejm RP, 2008) Sin embargo, hubo solo dos reuniones en este formato: en 2005 y 2010 (Brudzińska, 2013). 
En abril de 2017, tuvo lugar la primera visita del representante más alto de Polonia a México en los casi 90 años de historia de relaciones diplomáticas bilaterales. El presidente Duda fue recibido por el presidente Enrique Peña Nieto y tuvo oportunidad de pronunciar un discurso en el Senado (Senado de la República, 2017; Oficina de Presidente de Polonia, 2017). Importantemente, los dos líderes firmaron la Declaración hacia una asociación estratégica entre Polonia y México. Se aprobó también el plan de cooperación en el campo de educación y cultura para el período 2017-2021 (“Acta final de la IV reunión de la comisión mixta de cooperación educativa y cultural entre los Estados Unidos Mexicanos y la República de Polonia”, 2017)

Durante la visita del presidente Duda representantes de varias instituciones de ambos países firmaron memorandos y acuerdos de cooperación. Entre los documentos firmados se encontraban: declaración sobre cooperación entre el Ministerio de Fomento de Polonia y la Secretaría de Economía de México; memorando de cooperación entre la Agencia Polaca de Inversión y Comercio (PAIH) y ProMéxico; memorando sobre cooperación en el ámbito de los créditos a la exportación entre el Banco Nacional de Desarrollo polaco (BGK) y Bancomext; memorando de cooperación en el ámbito de los créditos a la exportación entre la Corporación de Seguros de Crédito a la Exportación (KUKE) y la Bancomext; acuerdo de cooperación técnica y científica en la exploración espacial y el uso del espacio con fines pacíficos entre la Agencia Espacial Polaca (POLSA) y la Agencia Espacial Mexicana (AEM) (Agencia Polaca de Inversiones y Comercio - PAIH, 2017).

Entre ejemplos de las reuniones de alto nivel en foros multilaterales merece la pena mencionar la Cumbre UE-América Latina y el Caribe en Guadalajara en mayo de 2004 con la participación de la delegación polaca encabezada por el presidente Kwaśniewski (Valdés-Ugalde \& Tigau, 2009). En mayo de 2008 el primer ministro Donald Tusk se reunió con el presidente Felipe Calderón en Lima durante la $5^{\text {a }}$ Cumbre UE-América Latina y el Caribe. La conversación se centró en el uso del marco UE-México para mejorar la cooperación económica bilateral y el apoyo de Polonia al establecimiento de una asociación estratégica de la Unión con México (Sejm RP, 2013a).

Las visitas ministeriales incluían la llegada a Polonia del Ministro de Relaciones Exteriores de México, José Antonio Meade Kuribreña en abril de 2015. Era ocasión para entregarle la solicitud oficial de Polonia para ser concedida el estatus de observador en la Alianza del Pacífico. En 2016, representantes del gobierno polaco remitieron una oferta de la cooperación con los Estados miembros del bloque a la 
Znojek., B.

presidencia chilena de la Alianza. La propuesta incluía el intercambio de experiencias en innovación, la internacionalización de las pymes y la revitalización de áreas urbanos.

El principal mecanismo de diálogo bilateral regular con los países de América Latina son las consultas entre las cancillerías a nivel de viceministros o directores departamentales. Son utilizadas para supervisar y determinar los rumbos de cooperación. En caso de algunos socios latinoamericanos el mecanismo funciona desde la década de 1990 (Wojna, 2006). En caso de México, el mecanismo se formalizó en 1998 aunque no ha sido utilizado con regularidad (Secretaría de Relaciones Exteriores México, 2016). En julio de 2018, la delegación mexicana con el vicecanciller Carlos A. de Icaza y el director general para Europa Francisco del Río viajaron a Varsovia. Los representantes de México se reunieron con el canciller Czaputowicz y se celebraron consultas intergubernamentales. Las partes emitieron un comunicado conjunto sobre el $90^{\circ}$ aniversario del establecimiento de relaciones diplomáticas polaco-mexicanas celebrado aquel año (Embajada de México en Polonia, 2018).

En diciembre de 2019, tuvo lugar la $12^{\mathrm{a}}$ edición de las consultas. Las delegaciones fueron encabezadas por los vicecancilleres: el polaco - Maciej Lang y el mexicano - Julián Ventura. Los principales temas tocados incluyeron el fortalecimiento del diálogo político y la cooperación económica en el contexto de las relaciones de la UE con México y en los ámbitos de educación, cultura y ciencia ("México y Polonia estrechan asociación estratégica tras 91 años de relación," 2019; Ministerio de Asuntos Exteriores de Polonia, 2019).

Entre otras reuniones intergubernamentales, cabe mencionar la visita a México entre septiembre y octubre de 2012 de una delegación polaca encabezada por la vicecanciller Beata Stelmach y con representantes de empresas polacas. El pretexto para la visita fueron actividades dentro de las "Jornadas de Polonia en México" (Sejm RP, 2013b). El evento consistió en la conferencia sobre el desarrollo del sector del petróleo y el gas de esquisto, el seminario económico bilateral "Polonia. Puerta a Europa" y la participación de Polonia como invitado honorario del Festival Cultural Internacional Cervantino en Guanajuato (Ministerio de Fomento de Polonia, 2017). En octubre de 2016, el secretario de estado en la Oficina de Presidente de Polonia Krzysztof Szczerski viajó a México para preparar la visita del presidente Duda al país (Cámara de Diputados, 2016)

Hablando de los importantes mecanismos del diálogo político cabe señalar la dimensión parlamentaria. Se trata principalmente de las actividades de los grupos bilaterales de amistad, que tienen 
un papel particular en fomentar interés político en los contactos y las visitas mutuas. Por ejemplo, en abril de 2004, México acogió a una delegación del Senado polaco que estaba de visita para participar en la reunión de la Unión Interparlamentaria (Sejm RP, 2004a) En julio de 2016, una delegación de senadores mexicanos estuvo en Polonia como parte de un viaje a varios países de la región. Durante la visita, representantes de las comisiones de asuntos exteriores y de la UE firmaron un memorando sobre cooperación y diálogo (Senado de la República, 2016).

Entre otras actividades parlamentarias merece mención también una iniciativa especial del Sejm - la cámara baja del Parlamento de Polonia - de las conferencias llamadas "Día de América Latina" organizadas en cooperación con la cancillería polaca y el Instituto Polaco de Asuntos Internacionales (PISM). Es actualmente el mayor evento oficial recurrente de este tipo que tiene como objetivo promover temas latinoamericanos en Polonia, incluso entre los miembros del parlamento. Hasta ahora se han celebrado dos ediciones (Sejm RP, 2017a, 2019a).

Separadamente es importante incluir reuniones con representantes de los estados mexicanos - por ejemplo, en 2005 una misión comercial de los gobernadores de estado de Jalisco y del estado de México (Sejm RP, 2013a). En el sistema unitario polaco, las regiones no tienen una posición tan fuerte y autonomía en la acción exterior, pero los gobiernos locales utilizan sus competencias para fomentar contactos internacionales. Sin embargo, el ejemplo principal han sido asociaciones entre ciudades con tales ejemplos como: Częstochowa - Zapopan, Jelenia Góra - Tequila, Łódź - Puebla y Wrocław Guadalajara. Éstas no necesariamente se tradujeron en unas relaciones activas y de contactos regulares. La dimensión del gobierno local sigue siendo un área prospectiva en las relaciones con socios latinoamericanos, especialmente los países federales como México (Skorupska \& Znojek, 2017).

Por último, hubo intentos de dialogar con México desde el Grupo de Visegrado - formado por Polonia, República Checa, Eslovaquia y Hungría. Hasta ahora tuvo lugar una reunión en este formato en 2014.

\section{Cooperación Económica}

Entre 2004 y 2019, la proporción de comercio con países latinoamericanos en el intercambio total de Polonia oscilaba entre el 1 y 1,24\%. Durante este período, la participación de México aumentó de 0.13\% a $0.25 \%$ (0.3\% siendo el número más alto registrado) lo que se tradujo en un salto de este país de $53^{\circ}$ a $42^{\circ}$ lugar entre los socios comerciales de Polonia - véase el Gráfico 1. Considerando sólo América Latina, 
Znojek., B.

en 2004 México fue el cuarto socio comercial de Polonia en la región, después de Brasil, Argentina y Panamá. En 2019, lo superaba solo Brasil, pero desde 2011 y con la excepción de años 2013-2014, México fue el principal mercado de exportación para Polonia en América Latina (Oficina Central de Estadística de Polonia - GUS, 2020). Ver gráfico 1.

\section{Gráfico 1.}

Comercio de bienes de Polonia con México en millones de dólares (2004-2019)

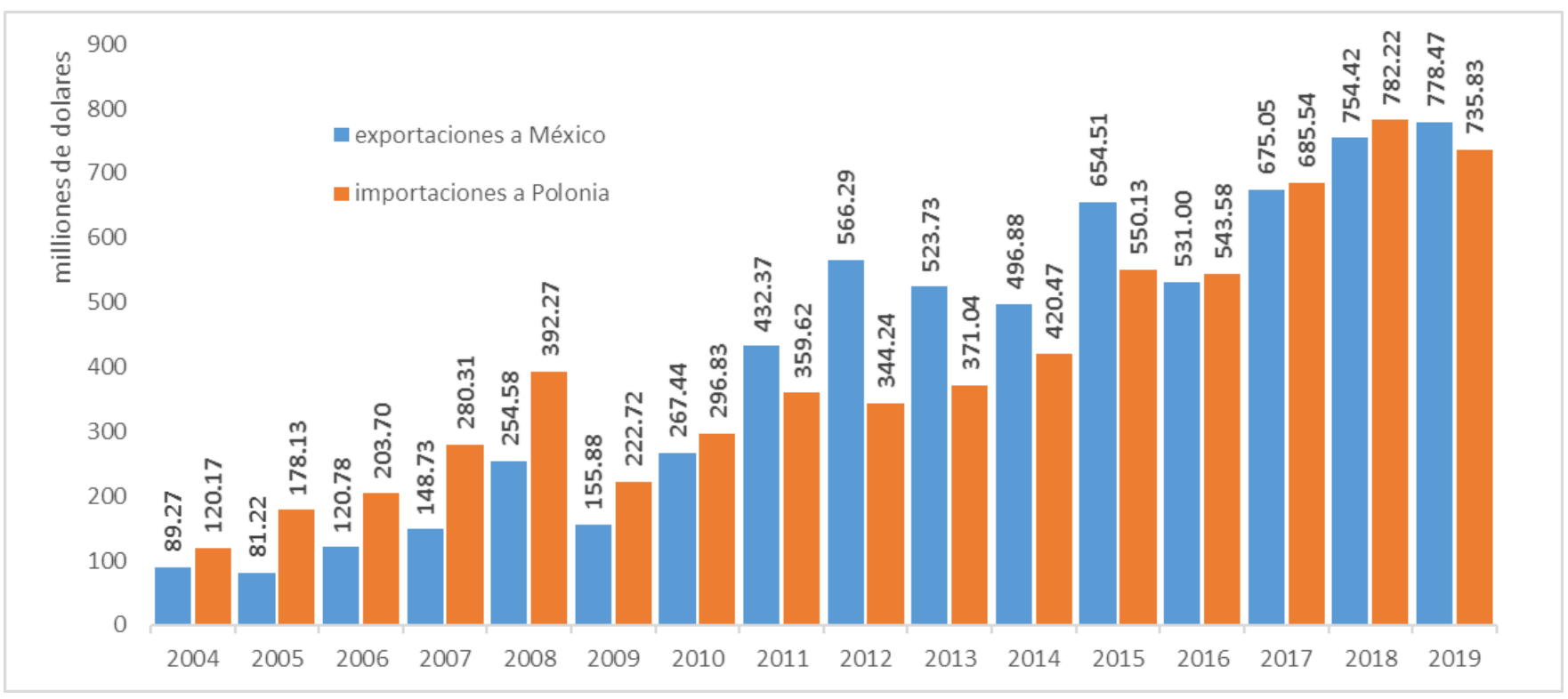

Fuente: Elaboración del autor a base de datos de la Oficina Central de Estadística de Polonia (GUS), swaid.stat.gov.pl (2020)

En 2004 casi la mitad de las mercancías importadas de México a Polonia eran teléfonos, maquinillas de afeitar, componentes electrónicos y dispositivos informáticos. En las exportaciones polacas, la mayoría eran piezas de automóviles (los motores solos constituían un tercio), leche en polvo, productos de papelería y vehículos. En 2019, la posición principal en las importaciones polacas desde México la tenían: maquinaria y equipos eléctricos, productos químicos (plásticos) y metalúrgicos. La estructura de las exportaciones polacas era similar con las máquinas y equipos eléctricos, vehículos y sus partes y los productos químicos. Según los datos de la Comisión Europea 1160 compañías polacas exportaban a México - dos tercios de ellas las pymes (Comisión Europea, 2020).

En el ámbito de la inversión, la presencia mutua sigue siendo pequeña, pero se puede notar un aumento gradual en la actividad de las empresas de ambos países en esta área. En 2019, había más de 50 
entidades con capital polaco en México, principalmente en la industria automotriz. Bury invirtió en el estado de Tlaxcala y Sanok Rubber Company en San Luis Potosí. Entre otros inversores cabe mencionar Inglot - una marca polaca de cosméticos - Tequila Águila en el estado de Jalisco y varias agencias polaco-mexicanas de viajes (Embajada de Polonia en México, 2020). En 2019, por ejemplo, Flyargo se interesó en entrar en el mercado mexicano con la intención de construir una fábrica de vehículos aéreos especiales.

Entre las empresas mexicanas presentes en Polonia cabe destacar CEMEX que entró en el mercado al adquirir el grupo británico RMC en 2004. Tiene dos plantas de cemento e invirtió en sectores vinculados. En 2006, el fabricante mexicano de autopartes Nemak compró las instalaciones manufactureras de TK Aluminium. En 2009, el holding automotriz Bienes Turgon se hizo dueño de la planta de combustión de la empresa Delphi en Błonie cerca de Varsovia - a través de su filial Katcon (Embajada de Polonia en México, 2020).

Las condiciones favorables para el fomento de las inversiones polaco-mexicanas se crearon con la entrada en vigor en 2003 del acuerdo bilateral sobre la evasión de la doble imposición y la prevención de la evasión fiscal firmado en 1998. El aumento del comercio tiene que ver con el acuerdo de la UE con México. Sin embargo, a pesar de las preferencias comerciales existentes, los obstáculos no arancelarios siguen siendo un problema por ejemplo para la venta de tales productos polacos como carne de cerdo y caucho sintético a México (Sejm RP, 2018).

Las dificultades mencionadas tienen que ver - entre otras causas - con las diferencias en el campo de las normas sanitarias y la clasificación de los productos, lo que afecta no solo Polonia sino también otros miembros de la UE. Por ejemplo, en diciembre de 2004 México suprimió el control fronterizo del nivel de radiación de los bienes polacos, lo que anteriormente obstaculizaba la exportación de productos lácteos de Polonia (Embajada de la República de Polonia en México, 2020). Las condiciones para el desarrollo de la cooperación comercial y la inversión deberán mejorarse substancialmente con la ratificación y entrada en vigor del acuerdo modernizado de la UE con México.

A parte del contexto legal, la crisis financiera global de 2008 fue un verdadero impulso para autoridades polacas que se hicieran más empeñadas en promover negocio polaco en los mercados menos conocidos, pero prometedores, como el de México. En consecuencia, se nota durante la próxima década un énfasis en la combinación de las delegaciones gubernamentales con las misiones de compañías polacas y en la creación de instrumentos de apoyo y promoción. En 2012 el Ministerio de Economía 
Znojek., B.

polaco puso en marcha un programa de apoyo para la entrada en unos mercados definidos como prometedores. Inicialmente solo Brasil fue seleccionado desde los países latinoamericanos. En 2013 se incluyó a México (más tarde se dejó a Brasil fuera debido a experiencias negativas de las empresas polacas que intentaban ingresar a su mercado). Otro programa llamado "Go to Brand” sirvió para apoyar empresas polacas en sectores específicos. México fue incluido en los programas destinados a las empresas de los sectores de nuevas tecnologías y el agroalimentario (Ministerio de Fomento, 2017).

En 2017, la Agencia Polaca de Inversiones y Comercio (PAIH) inicio el programa llamado Puentes Tecnológicos Polacos (PMT) que incluía México y los demás países del TLCAN: Canadá y Estados Unidos. El programa consistía en financiar proyectos de pymes interesadas en entrar en aquellos mercados (Sejm RP, 2018). En 2018, la Agencia Polaca de Desarrollo Industrial (PARP) puso en marcha un programa de apoyo a las actividades de promoción de las pymes en el marco del "Programa General de Promoción para los Emprendedores - MEXICO” con la duración planeada del 1 de marzo de 2018 al 31 de diciembre de 2019 (Agencia Polaca de Desarrollo Industrial - PARP, 2019).

Cabe destacar que en la segunda mitad de la década anterior las autoridades polacas iniciaron una substancial reforma del sistema oficial de promoción económica de Polonia. Hasta entonces, estas tareas estaban operadas por los departamentos económicos en embajadas o departamentos de promoción del comercio y la inversión (WPHI) con estatus diplomático y subordinados al ministerio responsable de la economía. En 2017, se comenzó el proceso de desmantelamiento de los WPHI y la creación de las Oficinas Exteriores de Comercio $(\mathrm{ZBH})$ - entidades sin estatus diplomático y subordinadas a PAIH. La primera entidad de este nuevo tipo en América Latina fue inaugurada en México durante la visita del presidente Duda. Entre las recientes iniciativas para el desarrollo de la cooperación económica, cabe mencionar la conferencia PAIH en junio de 2020 "México como una oportunidad de inversión para las empresas polacas - Panorama pospandemia COVID-19” organizado en cooperación con las cancillerías de Polonia y México.

Finalmente, vale la pena mencionar la actividad de las asociaciones de empresas. La Cámara Nacional de Comercio (KIG) en Polonia se distingue aquí. En 2004, KIG firmó un acuerdo de cooperación con el Consejo Mexicano de Comercio Exterior (COMCE). COMCE estableció un comité de empresarios polaco-mexicano para apoyar los contactos de compañías de ambos países. KIG también organizó seminarios en cooperación con la cancillería polaca por ejemplo sobre las oportunidades de 
negocio con la Alianza del Pacífico y países de América Central (Cámara Nacional de Comercio - KIG, 2017).

\section{Relaciones Socioculturales}

La cooperación en el ámbito de cultura y educación está regulada por el acuerdo bilateral de 1997 (en vigor desde 1998). Cuenta con una comisión mixta polaco-mexicana, que se reúne al menos cada cuatro años para aprobar programas bilaterales para períodos de unos años. Dado que no existe una institución oficial dedicada a la promoción cultural polaca en América Latina, la embajada de Polonia en México tiene papel destacado en este campo. Entre las actividades que emprende hay exposiciones, conciertos de música clásica y retrospectivas del cine polaco.

Entre las iniciativas importantes cabe destacar la participación de Polonia como invitado especial en el $7^{\circ}$ Festival Cultural de Mayo en Guadalajara en mayo de 2004 (Sejm RP, 2004a). En 2006, se presentó en la sede de los Archivos Nacionales de México una exhibición histórica "México y Polonia 1921-1945" basada en los archivos de la legación polaca en México.

Uno de los mayores eventos en el campo de la promoción cultural de Polonia en México fue “Jornadas de Polonia” en octubre de 2012. Polonia fue invitado honorario de la 40a edición del Festival Cultural Internacional Cervantino. El evento dio oportunidad a una de las mayores presentaciones de obras de artistas polacos en América Latina.

El festival fue inaugurado con el espectáculo musical Rock Jazz Chopin con la participación de la cantante de jazz Anna Serafińska, los pianistas Leszek Możdżer y Karol Radziwonowicz, y coreografías interpretadas por el grupo de danza Folies Dance Company. El programa de participación polaca en el evento también incluyó: la interpretación de Macbeth presentada por Teatr Pieśni Kozła, una exposición de carteles de ópera de Rafał Olbiński y una presentación de películas polacas de tales directores destacados como Jerzy Kawalerowicz, Jan Jakub Kolski e Juliusz Machulski. Además, hubo una presentación de una antología de cuentos de escritores polacos (de Bolesław Prus a Andrzej Stasiuk) titulada Elogio del cuento polaco y preparada por el escritor mexicano Sergio Pitol (Ministerio de Asuntos Exteriores de Polonia, 2012). Otros ejemplos de actividades culturales incluyen una retrospectiva de las películas de Andrzej Wajda y eventos relacionados con la celebración del 150 aniversario del nacimiento de la científica polaca Maria Skłodowska-Curie en 2018. 
En la promoción de Polonia en México merecen atención vínculos históricos comunes como la acogida de refugiados polacos por México en la colonia de Santa Rosa en la década de 1940. En 2013, se celebró el $70^{\circ}$ aniversario de la llegada de los refugiados polacos que abandonaron la Unión Soviética con el ejército del general polaco Władysław Anders. La diáspora polaca en México no es grande - según estimaciones es alrededor de 3 mil personas de la primera generación, con algunos siendo miembros de la élite cultural e intelectual mexicana (artistas, músicos, académicos) - y unos 15 mil descendientes de polacos principalmente judíos (Lepkowski, 1970; Sejm RP, 2013c, 2018; Smolana, 2018).

En el marco de los contactos entre personas, un área importante es el turismo. Según los datos de la Secretaría del Turismo de México, entre 2007 y 2018, el número de ciudadanos polacos que llegaban a México anualmente aumentó de más de 20 mil a más de 49 mil. (Secretaría del Turismo, 2018). En 2004, la Oficina Central de Estadística de Polonia (GUS) registró 11.4 mil llegadas de ciudadanos mexicanos a Polonia. En 2016, el número fue de 3.6 mil. En los años posteriores, los datos no están disponibles, pero se puede asumir que seguían siendo unos pocos miles (Oficina Central de Estadística - GUS, varios años).

En el campo de los contactos académicos, la cooperación polaco-mexicana tiene una historia bien desarrollada (Smolana, 2018). Durante mucho tiempo en la oferta oficial de becas, el único socio latinoamericano de Polonia fue México - ambos países ofrecían mutuamente siete becas al año. Sin embargo, en 2004, según GUS, 71 personas de países latinoamericanos estudiaron en las universidades polacas, la mayoría de Brasil (23), Ecuador (13) y Colombia (ocho). Según los últimos datos publicados, en 2018 los estudiantes latinoamericanos ya eran cerca de 400 personas - los mayores grupos nacionales siendo brasileños (106) y mexicanos (75) (Oficina Central de Estadística - GUS, 2019).

Desde 2004, han surgido numerosos acuerdos universitarios de Polonia y México. El creciente interés por la cooperación académica con la región se puso de evidencia en el nombramiento en 2015 de una plenipotenciaria para los contactos con América Latina bajo la presidencia de la Conferencia de Rectores de Universidades Polacas (KRASP). Ese hecho ha creado oportunidades para buscar una cooperación incluso más intensiva con las escuelas superiores mexicanas (Conferencia de Rectores de Universidades Polacas - KRASP, 2017).

En enero de 2018, KRASP y la Asociación Nacional Mexicana de Universidades e Instituciones de Educación Superior (ANUIES) firmaron un memorando de cooperación destinado a fomentar el 
intercambio de experiencias y de participación universitaria en iniciativas mutuas. Según los datos de una encuesta de ANUIES sobre la movilidad estudiantil en el año académico 2015/2016, había 50 estudiantes polacos en México y más o menos 200 estudiantes mexicanos en Polonia. En 2017, había más de 40 acuerdos de cooperación entre universidades de ambos países, de los cuales 17 con la Universidad de Varsovia (ANUIES, 2018).

La institución polaca que gestiona programas de becas e intercambios es la Agencia Nacional de Intercambio Académico (NAWA). La oferta incluye programas destinados a estudiantes de los países en desarrollo - en el caso de América Latina cuatro miembros de la Alianza del Pacífico pueden participar. Hay también un programa destinado a la diáspora polaca en el exterior lo que califica a los descendientes de polacos en los países latinoamericanos (Agencia Nacional de Intercambio Académico - NAWA, 2020). Polonia y México también están negociando acuerdos de cooperación en el campo de la cultura física y el deporte. Un acuerdo similar funciona, por ejemplo, con Colombia, permitiendo el intercambio de alumnos.

En caso de la cooperación científica y técnica, la base es el Acuerdo de 1998 (en vigor desde 2000). La implementación del acuerdo se lleva a cabo por iniciativas individuales de ambos países, ya que las partes no han establecido un órgano que defina los programas de cooperación como es el caso de compromisos en el campo cultura y educación. En el ámbito de la ciencia, los mecanismos de la UE son una plataforma importante de cooperación entre Polonia y México. Por ejemplo, en la $2^{\mathrm{a}}$ Cumbre UEMéxico de Ministros de Educación y Ciencia en 2005, Polonia se unió al grupo responsable de la realización y configuración de estos contactos (Sejm RP, 2008). La visita del presidente Duda a México en 2017 fue oportunidad de incentivar la cooperación en temas espaciales.

\section{3.- MÉTODO}

\section{Diseño}

El presente estudio está dedicado a la evolución de la política exterior polaca hacia México desde la entrada de Polonia en la Unión Europea en mayo 2004. La selección del tema surge de la constatación sobre un interés analítico muy limitado en las relaciones políticas contemporáneas de Polonia con México (y América Latina en sentido más amplio). Lo confirma la escasez de publicaciones. La estructura del análisis usa modelo empleado en los Anuarios de Política Exterior Polaca [polaco: Rocznik Polskiej 
Znojek., B.

Polityki Zagranicznej] - una publicación periódica del Instituto Polaco de Asuntos Internacionales (PISM).

Siguiendo el formato del Anuario la estructura de este texto consiste en presentar las condiciones más importantes, fundamentos y objetivos de la política del gobierno y finalmente de la presentación como fue la realización de esa política en el período investigado. Siguiendo ese modelo, el concepto de la política polaca hacia México se reconstruyó en la base de documentos oficiales y declaraciones de los representantes más altos del gobierno nacional, sobre todo los cancilleres polacos. Fue entonces un análisis del discurso público que consistió principalmente en buscar ocurrencias de las palabras claves como México, y más amplias como Alianza de Pacífico o América Latina. En cuanto a la realización de ese concepto se emplearon varias fuentes de instituciones estatales, medios de comunicación o centros de investigación. Ese conjunto de informaciones sirvió para recopilar y analizar los hechos y datos sobre las relaciones con México.

\section{Instrumentos}

En primer lugar, se revisaron extensamente las fuentes oficiales públicas - documentos del gobierno y declaraciones de los cancilleres durante las presentaciones anuales de los objetivos de la política exterior de Polonia en el parlamento polaco. También se revisó las audiciones en el parlamento de los candidatos para la posición de embajador de Polonia en México. En segundo lugar, se realizó una revisión de varias fuentes públicas para reconstruir el proceso de desarrollo de las relaciones polaco-mexicanas instituciones estatales, bases estadísticas, instituciones culturales y medios de comunicación.

\section{Procedimientos}

El primer paso consistió en recopilar fuentes relacionadas a las relaciones polaco-mexicanas desde el 2004. A base de todas las fuentes revisadas se formuló las condiciones más importantes que influían el proceso de la formulación de la política exterior polaca hacia México en el período investigado. El concepto de esa política se presentó con base de las declaraciones y documentos gubernamentales. Después se describió el proceso de la realización de esta política y del desarrollo de las relaciones polacomexicanas usando como referencia varias fuentes relacionadas a tres áreas: diálogo político, relaciones económicas y relaciones socioculturales. Finalmente se consideró hasta qué punto el concepto (objetivos principalmente) en la política hacia México fue cumplido. 


\section{4.- CONCLUSIONES}

Dada la prioridad que Polonia concede a las relaciones con sus socios en la UE, el vecindario y - fuera de Europa - con los Estados Unidos, es difícil esperar que los países de América Latina se vuelvan igualmente importantes. Sin embargo, evidentemente se nota un proceso gradual de fortalecimiento de la cooperación con los socios más grandes de la región - México en particular. La esfera económica no sólo es la de mayor importancia aquí, sino sirve como un catalizador para fomentar el interés en el diálogo político y otros ámbitos (cultura, educación, ciencia). El avance en las relaciones UE-México, incluida la firma de un nuevo acuerdo negociado en 2018, hace de México uno de los socios latinoamericanos más atractivos económica y políticamente para Polonia (Znojek, 2020).

La presencia de cuestiones mundiales en el diálogo con México es importante de punto de vista de las ambiciones de autoridades polacas de esforzar la imagen internacional de Polonia y conseguir tales objetivos como fue la membresía no permanente del Consejo de Seguridad de la ONU. Sin embargo, hay limitaciones aquí. Por ejemplo, la Alianza del Pacífico es un rumbo prometedor, pero Polonia tiene que competir con las ofertas de casi 60 otros países observadores en la organización. El bajo número de reuniones de representantes más altos refleja baja prioridad mutua de Polonia y México. La visita del Presidente Duda a México fue una excepción, pero sigue siendo un desafío para las autoridades de ambos países implementar los compromisos y declaraciones mutuas, en particular sobre el esfuerzo para construir una relación estratégica bilateral.

El principal factor impulsor para las relaciones bilaterales será la creciente presencia de las empresas polacas en México. Por lo tanto, el desarrollo del diálogo político polaco-mexicano debe servir principalmente para crear condiciones favorables para las actividades en las esferas de comercio e inversión mutuas. Sin embargo, existe un gran potencial para el desarrollo de contactos socioculturales, especialmente gracias a una base sólida de alto reconocimiento de México en Polonia y el interés mutuo en los campos de la cultura, la educación y la ciencia. Una de las maneras de fortalecer de la dimensión bilateral puede ser obtenida por el restablecimiento de las reuniones de expertos económicos en la fórmula del llamado "think tank". Además, se puede considerar un mecanismo de diálogo similar entre instituciones expertas de Polonia y México. 
Znojek., B.

\section{REFERENCIAS}

Acta final de la IV reunión de la comisión mixta de cooperación educativa y cultural entre los Estados Unidos Mexicanos y la República de Polonia. (2017). https://transparencia.sre.gob.mx/transparencia-categorias/category/388-fracc-vi-e-tratadosinternacionales-celebrados-y-en-vigor-para-mexico

Agencia Nacional de Intercambio Académico - NAWA. (2020). NAWA Programmes. https://nawa.gov.pl/en/nawa-programmes

Agencia Polaca de Inversiones y Comercio - PAIH. (2017). Meksyk. Przewodnik po rynku. https://www.paih.gov.pl/files/?id_plik=31409

Agencia Polaca de Desarrollo Industrial - PARP. (2019). Program promocji o charakterze ogólnym dla przedsiębiorców - MEKSYK. https://www.parp.gov.pl/storage/grants/documents/41/PPOMeksyk-obowizuje-od-21.02.18.pdf

ANUIES. (31 de enero de 2018). Fortalecen cooperación académica México y Polonia, Comunicado de Prensa. http://www.anuies.mx/media/docs/avisos/pdf/180201123145ANUIES+Polonia.pdf

Brudzińska, K. (mayo de 2013). Polish-Mexican Cooperation: Where Does Poland Stand? PISM Policy Paper, 12 (60). Varsovia: Instituto Polaco de Asuntos Internacionales (PISM). https://pism.pl/publications/PISM_Policy_Paper_no_12_60__Polish_Mexican_Cooperation _Where_Does_Poland_Stand_.

Cámara Nacional de Comercio - KIG. (20 de junio de 2017). Seminarium: Sojusz Pacyfiku gospodarcze wyzwanie dla Polski. https://kig.pl/relacja-seminarium-sojusz-pacyfikugospodarcze-wyzwanie-dla-polski-20-06-2017/

Cámara de Diputados. (2016). Polonia, socio confiable y digno en el negocio internacional: María Ávila Serna (Nota Núm. 4652). http://www5.diputados.gob.mx/index.php/esl/Comunicacion/Agenciade-Noticias/2016/10-Octubre/20/4652-Polonia-socio-confiable-y-digno-en-el-negociointernacional-Maria-Avila-Serna

Comisión Europea. (2020). Negotiations and agreements EU-Mexico Association Agreement EUMexico in your town, Factsheet: Poland. https://ec.europa.eu/trade/policy/in-focus/eu-mexicotrade-agreement/eu-mexico-in-your-town/poland_en.htm

Conferencia de Rectores de Universidades Polacas - KRASP. (2017). Sprawozdanie z działalności Konferencji Rektorów Akademickich Szkót Polskich za rok 2016, przedstawione przez Przewodniczacego KRASP na posiedzeniu Zgromadzenia Plenarnego KRASP w dniu 9 czerwca 
https://www.krasp.org.pl/resources/upload/dokumenty/dokumenty_ro\%C5\%BCne/sprawozdani a/sprawozdanieza_rok_2016.pdf

Consejo de Ministros del Gobierno de Polonia. (marzo de 2012). Priorytety polskiej polityki zagranicznej 2012-2016.

https://web.archive.org/web/20121221003417/http://www.msz.gov.pl/pl/polityka_zagraniczna/ priorytety_polityki_zagr_2012_2016[versión archivada de la página]

Embajada de México en Polonia. (2018). Comunicado Conjunto: México y Polonia celebran 90 años de relaciones diplomáticas. https://embamex.sre.gob.mx/polonia/index.php/avisosimportantes/146-comunicado-conjunto-mexico-y-polonia-celebran-90-anos-de-relaciones

Embajada de Polonia en México. (2020). Relacje dwustronne. Meksyk. https://www.gov.pl/web/meksyk/stosunki-dwustronne

Hinz, K. J. (elaboración). (2015). Wyzwania w polityce zagranicznej RP wobec Ameryki Łacińskiej $i$ Karaibów 2015-2020 i po 2020 r. Varsovia: Ministerio de Asuntos Exteriores de Polonia Departamento de las

Américas.

https://issuu.com/msz.gov.pl/docs/wyzwania_dla_polityki_zagranicznej_51b9f4684c6f30

Łapaj-Kucharska, J. (2020), Polityka zagraniczna Polski wobec Ameryki Lacińskiej w okresie zimnowojennym. Prace naukowe Uniwersytetu Śląskiego w Katowicach nr 3915. Katowice: Wydawnictwo Naukowe Uniwersytetu Śląskiego.

https://wydawnictwo.us.edu.pl/sites/wydawnictwo.us.edu.pl/files/wus_2020_lapaj-

kucharska_polityka_zagraniczna_polski_wobec_ameryki.pdf

Łepkowski, T. (1970). Z dziejów kontaktów polsko-meksykańskich w XIX i XX w. Etnografia Polska, 14(2), 75-94.

México y Polonia estrechan asociación estratégica tras 91 años de relación. (11 de diciembre de 2019). El Economista. https://www.eleconomista.com.mx/internacionales/Mexico-y-Polonia-estrechanasociacion-estrategica-tras-91-anos-de-relacion-20191211-0060.html

Ministerio de Fomento de Polonia. (13 de junio de 2017). Notatka nt. polsko-meksykańskiej wspótpracy gospodarczej. http://archiwum.miir.gov.pl/media/39377/Meksyk_13_06_2017.pdf

Ministerio de Asuntos Exteriores de Polonia. (noviembre de 2004). Strategia RP w odniesieniu do pozaeuropejskich krajów rozwijajacych się. Varsovia. [Documento en los recursos privados del autor, no disponible más en la página del ministerio] 
Znojek., B.

Ministerio de Asuntos Exteriores de Polonia. (2012). Polska inauguruje Festiwal Cervantino. http://meksyk.msz.gov.pl/pl/wspolpraca_dwustronna/kultura/wydarzenia_kulturalne/inauguracj afic [Documento en los recursos privados del autor, no disponible más en la página del ministerio] Ministerio de Asuntos Exteriores de Polonia. (enero de 2017). Strategia Polskiej Polityki Zagranicznej 2017-2021. https://www.gov.pl/attachment/8196524f-687b-40e6-aca8-82c53ff8e6db

Ministerio de Asuntos Exteriores de Polonia. (11 de diciembre de 2019). Polsko-meksykańskie konsultacje polityczne. https://www.gov.pl/web/dyplomacja/polsko-meksykanskie-konsultacjepolityczne

Oberda-Monkiewicz, A. (2017). Evolution of EU-Mexico relations: time for real partnership? Anuario Latinoamericano Ciencias Políticas y Relaciones Internacionales, 4, 187-202. https://doi.org/10.17951/al.2017.4.187

Oficina Central de Estadística - GUS. (varios años). Turystyka. www.stat.gov.pl

Oficina Central de Estadística - GUS. (2019). Szkoły wyższe i ich finanse w 2018 r. (Informacje statystyczne). Warszawa, Gdańsk. https://stat.gov.pl/obszarytematyczne/edukacja/edukacja/szkoly-wyzsze-i-ich-finanse-w-2018-roku,2,15.html

Oficina Central de Estadística - GUS. (2020). Baza SWAID. swaid.stat.gov.pl

Oficina de Presidente de Polonia. (14 de mayo de 2004). Wizyta oficjalna Prezydenta Meksykańskich Stanów Zjednoczonych z Matżonka - śniadanie oficjalne. https://www.prezydent.pl/archiwalneaktualnosci/rok-2004/art,256,wizyta-oficjalna-prezydenta-meksykanskich-stanowzjednoczonych-z-malzonka-sniadanie-oficjalne.html

Oficina de Presidente de Polonia. (25 de abril de 2017). Polska chce świata zbudowanego na wspótpracy. https://www.prezydent.pl/aktualnosci/wypowiedzi-prezydenta-rp/wystapienia/art,197,polskachce-swiata-zbudowanego-na-wspolpracy.html

Secretaría de Relaciones Exteriores México. (2016). Recomendaciones para el fortalecimiento de la relación entre México. Zalecenia dotyczace wzmocnienia relacji między Polska a Meksykiem. Secretaría de Relaciones Exteriores - Instituto Matías Romero. www.sre.gob.mx

Secretaría del Turismo. (2018). Compendio Estadístico del Turismo en México 2018. Www.datatur.sectur.gob.mx

Sejm RP. (17 de junio de 2004a). Biuletyn z posiedzenia Komisji Spraw Zagranicznych (nr 183) (No. $3286 / I V)$.

http://orka.sejm.gov.pl/Biuletyn.nsf/31a5e0f7750d0317c1256b2900339858/4c4aa4434951d9e3 c1256ec4003eb498?OpenDocument 
Sejm RP. (21 stycznia 2004b). Informacja ministra spraw zagranicznych o zadaniach polskiej polityki $\begin{array}{lllll}\text { zagranicznej } & \text { 2004 } & \text { roku. } & \text { Sejm }\end{array}$ http://orka2.sejm.gov.pl/Debata4.nsf/118b9e577f3fceeac125746d0030d0fa/69dd0dabff098e40c 1257478003daba8

Sejm RP. (29 de octubre de 2008). Biuletyn z posiedzenia Komisji Spraw Zagranicznych (nr 74) (No. 1442/VI). Varsovia: Kancelaria Sejmu - Biuro Komisji Sejmowych. http://orka.sejm.gov.pl/Biuletyn.nsf/0/F63C45DF96FFCC3DC1257504003842D9?OpenDocum ent

Sejm RP. (29 de marzo de 2012). Informacja Ministra Spraw Zagranicznych o założeniach polskiej $\begin{array}{llll}\text { polityki zagranicznej } & w & 2012 & \text { roku. }\end{array}$ http://www.sejm.gov.pl/sejm7.nsf/wypowiedz.xsp?posiedzenie=11\&dzien=2\&wyp=2\&view=4

Sejm RP. (10 de mayo de 2013a). Odpowiedź podsekretarza stanu w Ministerstwie Gospodarki - z upoważnienia ministra - na interpelacje $n r 16991 \mathrm{w}$ sprawie umowy o bezcłowym handlu $z$ Meksykańskimi Stanami Zjednoczonymi. http://www.sejm.gov.pl/sejm7.nsf/InterpelacjaTresc.xsp?key=3EDF909C

Sejm RP. (18 de enero de 2013b). Odpowiedź podsekretarza stanu w Ministerstwie Spraw Zagranicznych - z upoważnienia ministra - na interpelacje nr 12921 w sprawie kontaktów handlowych $z$ Meksykańskimi Stanami Zjednoczonymi. http://www.sejm.gov.pl/sejm7.nsf/InterpelacjaTresc.xsp?key=5EC82891

Sejm RP. (2013c). Petny zapis posiedzenia Komisji Spraw Zagranicznych (nr 100). Varsovia: Kancelaria Sejmu - Biuro Komisji Sejmowych. http://orka.sejm.gov.pl/zapisy7.nsf/0/92F964FA32C00AE9C1257BFF004AF23B/\%24File/023 7407.pdf

Sejm RP. (23 de abril de 2015). Informacja ministra spraw zagranicznych o zadaniach polskiej polityki zagranicznej $w 2015 \quad r$. http://www.sejm.gov.pl/sejm7.nsf/wypowiedz.xsp?posiedzenie=91\&dzien=2\&wyp=37\&view= 4

Sejm RP. (29 de enero de 2016). Informacja ministra spraw zagranicznych o zadaniach polskiej polityki zagranicznej w 2016 roku. En Sprawozdanie stenograficzne z 10. posiedzenia Sejmu Rzeczypospolitej Polskiej $w$ dniu 29 stycznia 2016 r. (drugi dzień obrad). http://orka2.sejm.gov.pl/StenoInter8.nsf/0/6A4CD2F71231A36FC1257F4D003FECA4/\%24Fil e/10_b_ksiazka_bis.pdf 
Znojek., B.

Sejm RP. (19 de noviembre de 2017a). Dzień Ameryki Łacińskiej w Sejmie - zapowiedź. http://www.sejm.gov.pl/sejm8.nsf/komunikat.xsp?documentId=1540F7FFB12F6E1AC12581D D002AE9A7

Sejm RP. (9 de febrero de 2017b). Informacja ministra spraw zagranicznych o zadaniach polskiej polityki zagranicznej w 2017 roku. En Sprawozdanie stenograficzne z 35. posiedzenia Sejmu Rzeczypospolitej Polskiej w dniu 9 lutego 2017 r. (drugi dzień obrad). http://orka2.sejm.gov.pl/StenoInter8.nsf/0/8E7E4FB126949A76C12580C3000D81A5/\%24File/ 35_b_ksiazka_bis.pdf

Sejm RP. (6 de junio 2018). Petny zapis posiedzenia Komisji Spraw Zagranicznych (nr 111). Varsovia: Kancelaria Sejmu - Biuro Komisji Sejmowych. http://orka.sejm.gov.pl/zapisy8.nsf/0/E77D04EFD16E711CC12582AB004B9E91/\%24File/031 9808.pdf

Sejm RP. (9 de setiembre de 2019a). II Dzień Ameryki Łacińskiej w Sejmie. Zapowiedź (11 września). https://www.sejm.gov.pl/Sejm8.nsf/komunikat.xsp?documentId=75D8B485378D9D16C12584 700044605A

Sejm RP. (14 de marzo de 2019b). Informacja ministra spraw zagranicznych o zadaniach polskiej polityki zagranicznej $w 2019 \quad$ roku. Sejm http://www.sejm.gov.pl/sejm8.nsf/wypowiedz.xsp?posiedzenie=78\&dzien=2\&wyp=3\&view=4

Senado de la República. (2016). Visita de trabajo de una delegación del Senado de la República a la Federación Rusa, Finlandia, Polonia y Georgia (Informe, Centro de Estudios Internacionales Gilberto Bosques). http://transparencia.senado.gob.mx/obligaciones/LGART70/FRAC-IX/CI16-044-SEN03_INF.pdf

Senado de la República. (25 de abril de 2017). Visita del señor Andrzej Duda, presidente de La República de Polonia. Diario de los Debates, LXIII Legislatura, Año II, Sesión núm. 28. https://www.senado.gob.mx/64/diario_de_los_debates/documento/2901

Skorupska, A., \& Znojek, B. (2 de octubre de 2017). The Local Government Dimension of Relations between Poland and Latin America. Biuletyn PISM. Varsovia: Instituto Polaco de Asuntos Internacionales

(PISM). https://www.pism.pl/publications/The_Local_Government_Dimension_of_Relations_between_ Poland_and_Latin_America

Smolana, K. (2018). Polska i Meksyk na przestrzeni dziejów widziane z perspektywy misji dyplomatycznej/Polonia y México a lo largo de la historia: una perspectiva de la misión 
diplomática polaca. (E. Kwiatkowska-Faryś, traducción). México: Secretaría de Relaciones Exteriores, Instituto Matías Romero. https://issuu.com/embajadadepoloniaenmexico/docs/polonia-me_xico-final_web

Valdés-Ugalde, J. L., \& Tigau, C. (2009). Beyond Politics: Cultural Connections Among Mexico, Romania and Poland. Voices of Mexico, January-April (84), 75-78. www.revistascisan.unam.mx/Voices/

Wojna, B. (2006). Polska polityka wobec Ameryki Łacińskiej i Karaibów - bilans i możliwości rozwoju stosunków z perspektywy członkostwa w Unii Europejskiej. Polski Przegląd Dyplomatyczny, 4 (32), 49-65. Varsovia: Instituto Polaco de Asuntos Internacionales (PISM).

Znojek, B. (2018). Ameryka Łacińska w polityce zagranicznej Polski od 2004 r. En Rocznik Polskiej Polityki Zagranicznej 2017. Varsovia: Instituto Polaco de Asuntos Internacionales (PISM).

Znojek, B. (29 de enero de 2020). The Course of Changes in Mexican Foreign Policy. Bulletin PISM. Varsovia: Instituto Polaco de Asuntos Internacionales (PISM). https://www.pism.pl/publications/The_Course_of_Changes_in_Mexican_Foreign_Policy 